\title{
Deglycosylated Ricin A Chain-Conjugated Anti-CD19/Anti-CD22 Immunotoxins
}

National Cancer Institute

\section{Source}

National Cancer Institute. Deglycosylated Ricin A Chain-Conjugated Anti-CD19/Anti-CD22

Immunotoxins. NCI Thesaurus. Code C67061.

A combination preparation of 1:1 mixture of two immunotoxins, HD37-dgA and RFB4dgA, with potential antineoplastic activity. Both anti-CD19 Ig G monoclonal antibody HD37 and anti-CD22 IgG monoclonal antibody RFB4 are attached to a single deglycosylated ricin A chain (dgA) via N-succinimidyl-oxycarbonyl-alpha-methyl-alpha-(2pyridyldithio) toluene (SMPT) linker. CD19 and CD22 molecules are cell suface antigens present on the majority of B acute lymphoblastic leukemia cells. This combination agent is able to specifically recognize and bind to CD19 and CD22 expressing tumor cells, thereby targeting the delivery of the cytotoxic ricin A chain to leukemia cells expressing these antigens. Ricin A chain is toxic to ribosomal activity and protein synthesis, and inhibits cell growth. 